\title{
Simulation Study on the Mechanism and Factors of Forestry Carbon Sequestration Market Development
}

\author{
Fei Long ${ }^{1}$ and Huibo $\mathrm{Qi}^{2}, *$ \\ ${ }^{1}$ School of Economics and Management, Zhejiang A \& F University, Hangzhou, China \\ ${ }^{2}$ School of Economics and Management, Zhejiang A \& F University, Hangzhou, China \\ *Corresponding author
}

\begin{abstract}
This paper aims to analyze the mechanism and factors of forestry carbon sequestration market development. It is concluded that there is great development potential in the forestry carbon sequestration market of Zhejiang Province and all of the market subjects make active response to the market, which will provide favorable internal conditions for market expansion, and it is conductive to mitigate the carbon emission and cope with the climate changes through forestry carbon sequestration. In addition, this paper constructs a carbon transaction price conversion coefficient model based on market mechanism, calculates the conversion rate of Zhejiang traditional forestry management into carbon sequestration forestry management in different carbon price and then carries out a simulation of the development trend of Zhejiang forestry management. The results show that carbon price of Zhejiang voluntary carbon market will rise from the current 110 Yuan to 1100 Yuan in future 20 years. Rational forestry management subjects will continue to realize the conversion from traditional forestry management to carbon sequestration forestry management, and the conversion rate will achieve at 0.875 . In the end, this paper discuses and explains the relevant factors restricting the development of Zhejiang voluntary carbon market.
\end{abstract}

Keywords-forestry carbon sequestration market; mechanism; factors; simulation

\section{INTRODUCTION}

Forestry carbon sequestration is the most economical way of carbon sequestration in the world. In China, the governments always attach great importance to the forestry and emphasize the important function of forests, so the corresponding policies have been unveiled. The main subjects in forestry carbon sequestration market are the suppliers and demanders. The suppliers are those who own or manage forest resources, including farmers, village collectives and other individuals, enterprises and entities that own or manage forest resources. According to Kyoto Protocol, the global demanders of forestry carbon sequestration mainly include the enterprises or entities that are forced to reduce the greenhouse gas emission by the climate change policies as well as the governments, some investment corporations, the private environmental-protection organizations and the general public ${ }^{[1]}$. In addition, as a participant and controller in the forestry carbon sequestration market, the government is also an important market subject to push forward the market development.

The response mechanism of subjects in the forestry carbon sequestration market to market development refers to the process in which the market subjects actively interact with each other to expand the market and make the market mature through reasonable decision-making ${ }^{[2]}$. As a result, to analyze the response mechanism of subjects in forestry carbon sequestration market to market development, we first make an analysis of the behavior characteristics of subjects in the forestry carbon sequestration market and then get a clear understanding of the resource base, information channels, policy environment and management measures, which provides a scientific way to better analyze the foundation, paths and dynamic mechanism of the forestry carbon sequestration market development.

\section{RESEARCH DESIGN}

\section{A. Sample Survey}

The research chooses the regions in Zhejiang Province where there are abundant forestry resources or the projects of forestry carbon sequestration have been implemented, then the samples are chosen according to the degree of forestry resource abundance and whether the projects of forestry carbon sequestration have been implemented or not. The surveys contains 350 samples from farmer households and 300 samples from village collectives come from 5 counties and cities including Linan, Anji, Suichang, Cangnan and Kaihua. The surveys on emission-reduction enterprises and the pubic mainly reflect the situation of demanders in the forestry carbon sequestration market (150 samples from the emission-reduction enterprises and 1000 samples from the public) and the enterprise samples mainly come from the developed cities, including Hangzhou, Ningbo, Jiaxing and Hangzhou [3]. The samples are randomly selected from the public via the Internet survey. Through the survey on the government departments, we can understand the policy implementation and the role of government in the forestry carbon sequestration trade (100 samples selected from the key information suppliers in functional departments on the provincial, municipal and county level.

\section{B. Statistical Description}

Through sorting out investigation data, it can be found fom Table 1 and Table 2 that there is great development potential in the forestry carbon sequestration market of Zhejiang Province and all of the market subjects make active response to the market development: the demand subject's willingness to pay for forestry carbon sequestration reaches up to $76.2 \%$, the suppliers' willingness to be engaged in the forestry carbon sequestration trade reaches up to $82.6 \%$, and the governments' willingness to push forward the market development reaches up 
to $89.3 \%$. Although the project groups show that all of the market subjects in Zhejiang Province respond well to the forestry carbon sequestration market development, there are several problems in building the specific response mechanism and these problems will be analyzed in detail in the following chapter.

TABLE I. FARMERS AND VILLAGE COLLECTIVES' RESPONSE TO FORESTRY CARBON SEQUESTRATION TRADE

\begin{tabular}{lcc}
\hline Survey Items & Answers & Percentage(\%) \\
\hline Do you know forests can absorb carbon & Yes & 81.2 \\
dioxide? & No. & 18.8 \\
& Yes. & 33.7 \\
Do you know carbon sequestration? & No. & 66.3 \\
Are you willing to be engaged in carbon & Yes. & 82.6 \\
sequestration trade & No. & 27.4 \\
Are you willing to change the mode of business & Yes. & 79.1 \\
operation? & No. & 20.9 \\
\hline
\end{tabular}

TABLE II. ENTERPRISES AND THE PUBLIC'S RESPONSE TO FORESTRY CARBON SEQUESTRATION TRADE

\begin{tabular}{|c|c|c|}
\hline Survey Items & Answers & Percentage $(\%)$ \\
\hline Is the climate abnormal? & Yes. & 88.7 \\
\hline Responsibility for mitigating climate change & $\begin{array}{l}\text { Decided by } \\
\text { the amount } \\
\text { of carbon } \\
\text { emitted }\end{array}$ & 89.1 \\
\hline $\begin{array}{l}\text { Is it necessary for enterprises and individuals to } \\
\text { reduce carbon emission? }\end{array}$ & Yes. & 96.4 \\
\hline $\begin{array}{l}\text { Are you willing to pay for the carbon emitted } \\
\text { by yourself? }\end{array}$ & Yes. & 82.6 \\
\hline $\begin{array}{l}\text { Do you know forests can absorb carbon } \\
\text { dioxide? }\end{array}$ & Yes. & 49.7 \\
\hline $\begin{array}{l}\text { Should the forestry carbon sequestration be } \\
\text { paid? }\end{array}$ & Yes. & 72.3 \\
\hline $\begin{array}{l}\text { Are you willing to pay for forestry carbon } \\
\text { sequestration? }\end{array}$ & Yes. & 76.2 \\
\hline
\end{tabular}

Data source: questionnaires

\section{FACTORS OF FORESTRY CARBON SEQUESTRATION MARKET}

\section{A. Economic Resource Base}

Zhejiang Province is rich in forest resources. Especially since the reform and opening-up, the forestry industry has been rapidly developed. In 2017, the total social output value of forestry industry in Zhejiang amounted to 532.6 billion Yuan, ranking among the highest in our country. Meanwhile, there are two carbon sequestration afforestation projects of China Green Carbon Funds in Zhejiang and one is in Linan and another in Cangnan County; and there is Wenzhou Special Project, which is the first special fund to a prefecture-level city in our country $^{[4]}$; all these have laid a favorable resource and practice foundation for Zhejiang to carry out the work.

\section{B. Information Channels}

There are some factors that influence the forest managers' decision-making on carbon sequestration forest planting and trade. Although forest managers have been engaged in the carbon sequestration forest planting for a long time, they still lack a theoretical cognition to the forestry carbon sequestration trade and pay little attention to the forestry carbon sequestration trade information ${ }^{[5,6]}$. In addition, the government and village committee are the two main channels for the forest managers to obtain the forestry carbon sequestration information and both of the two channels have played a huge role in the forest managers' carbon sequestration planting. Besides, radios and TVs are another channel for the forest managers to obtain information.

\section{Government Support and Service}

$48.88 \%$ of the forest managers obtain the trade information from government and village committee and $93 \%$ of the forest managers believes the governments have helped them a lot. For the carbon sequestration forest planting, the government plays an important role in popularizing the idea, providing planting technique, releasing the trade information and improving the infrastructure. While the forest managers encounter some emergencies such as fire and pest and disease damage in carbon sequestration planting, the local governments lack a series of perfect emergency measures. So the forest managers hope the government can quickly establish a set of measures for the unexpected needs.

\section{Management Measures}

In the survey on the forest managers' satisfaction with using new technologies, $40 \%$ of the forest managers are dissatisfied with using new technologies and the traditional technologies can largely meet the demands of carbon sequestration forest planting. In the management of carbon sequestration forest, $62.07 \%$ of the forest managers can adjust their management of carbon sequestration forest to the market demands. There are limited channels for the forest managers to obtain the carbon sequestration information and the forest managers find it difficult to understand the profound carbon sequestration information.

\section{MeChanism OF Forestry CARbon SEQUESTRATION MARKET}

According to the above analysis of subject elements of Zhejiang voluntary carbon market, we construct a carbon transaction price conversion coefficient model to reflect the market mechanism ${ }^{[7,8]}$. Correlated variables include supply response index of forest managers' subjects, demand response index of enterprises and the public, government policy boosting response index as well as economic resource and infrastructure promotion index etc. The specific conversion coefficient rule form is as follows:

$$
P C_{(s, t)}=\frac{1}{1+\exp \left[-\left(d+C S_{(s, t)}+\sum_{t} S B_{s} \cdot E_{s}\right)\right]} \times C D_{(s, t)} \times G P_{(s, t)}
$$

Where, $P C_{(\mathrm{s}, \mathrm{t})}$ is carbon transaction price conversion coefficient; $\mathrm{d}$ is logistic regressive constant; $C S_{(\mathrm{s}, \mathrm{t})}$ means supply response index of forest managers subjects; $S B_{\text {s }}$ represents present economic resource utilization and infrastructure construction conditions; $E_{\mathrm{s}}$ represents increasing speed index of economic resource utilization and infrastructure construction conditions; the summation of the product of $S B$ and $E$ along the time $t$ means aggregated increase value of economic resource and infrastructure; $C D_{(\mathrm{s}, \mathrm{t})}$ indicates demand 
response index of enterprises and the public; $G P_{(\mathrm{s}, \mathrm{t})}$ indicates government market boosting response index; $s$ is the initial time of simulation; $t$ is the setting time of simulation scene.

In accordance with carbon transaction price conversion coefficient rule in different times, we can calculate carbon transaction price level in different times. The model is:

$$
P C_{t}=P C_{s} \cdot P C_{(s, t)}
$$

Where, $\mathrm{PC}_{\mathrm{t}}$ and $\mathrm{PC}_{\mathrm{s}}$ means carbon transaction price level in different times and initial time respectively.

At different carbon transaction prices, we assume forestry managers (individual farmers and village collective) as rational decision-making subjects and they will make a choice between two management models (traditional/carbon sequestration forestry management model) and continuously carry out management conversion. Besides, we assume such conversion process complies with random walk principle of rational decision-making subject in decision behavioral science ${ }^{[9]}$. Then, management conversion model is constructed at different carbon transaction price in which forestry managers transform to carbon sequestration forestry management model from traditional forestry management model:

$$
\begin{aligned}
C R_{s, t} & =E\left[V\left(\Delta P_{t}\right)-V\left(\Delta P_{s}\right) \mid V(\cdot) \in P C_{t}(\cdot) / P C_{s}(\cdot)\right] \\
& \cong V^{\prime}(\cdot) E\left[\Delta P_{t}-\Delta P_{s}\right]
\end{aligned}
$$

According to random system limit theory, we get the following model:

$$
\sum_{t=T}^{\infty} E\left[V\left(\Delta P_{t}\right)-V\left(\Delta P_{s}\right) \mid V(\cdot)\right] \leq \sum_{t=T}^{\infty}-\frac{t}{t+1+V(\cdot)}=-\infty
$$

Where, $C R$ means management conversion rate of forestry managers transforming to carbon sequestration forestry management model from traditional forestry management model at different carbon transaction prices; $V(\Delta P)$ indicates distance function of $\Delta P$ between the average price of various woods and carbon sequestration price in different times. In accordance with statistical data of State Forestry Bureau, the average price of various woods is 1315 Yuan ${ }^{[10]}$. Besides, it is assumed that in future 20 years the average price of various woods in Zhejiang will rise at the speed of $6.8 \%{ }^{[11]}$. According to the above formula, we can calculate management conversion rate of forestry managers transforming to carbon sequestration forestry management model from traditional forestry management model at different carbon transaction prices.

\section{SimUlation OF ZHEJIANG FoRESTRY MANAGEMENT}

According to the above model (1), we utilized Matlab software to calculate carbon transaction price conversion coefficient in Zhejiang, i.e. 1.037. The current international carbon price is USD $17.54^{[12]}$ (amounting to RMB 110 Yuan). Based on this carbon price, we assume each subject element on Zhejiang voluntary carbon market continues to actively respond to the market development. In accordance with Decision on Boosting Ecological Civilization Construction made by Zhejiang, economic resource utilization and infrastructure construction will be improved and increased at the speed of less than $1.73 \%$ annually. On this basis, the carbon price trend of Zhejiang voluntary carbon market in future 20 years is shown in Figure 1.

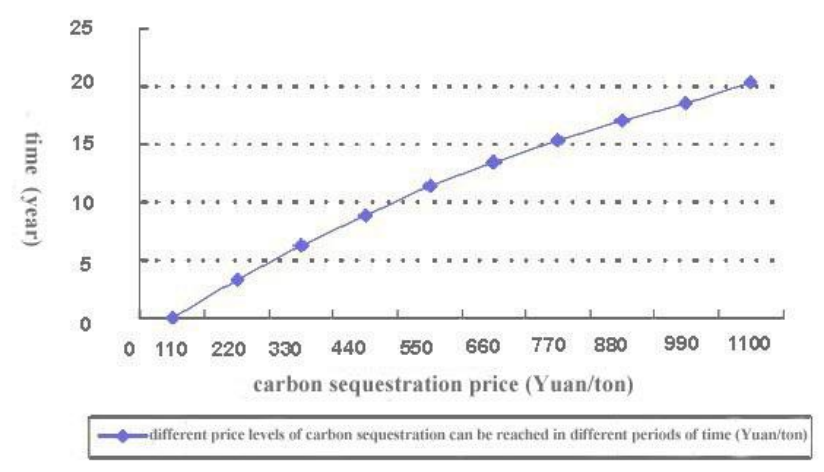
FIGURE I. CARBON TRANSACTION PRICE OF ZHEJIANG IN
FUTURE 20 YEARS

As can be seen from the above figure, carbon transaction price of Zhejiang in future 20 years will rise from current 110 Yuan to 1100 Yuan. With the continuous rise in carbon price, rational forestry management subject will continue to realize the conversion from traditional forestry management to carbon sequestration forestry management. Figure 2 shows the specific conversion process.

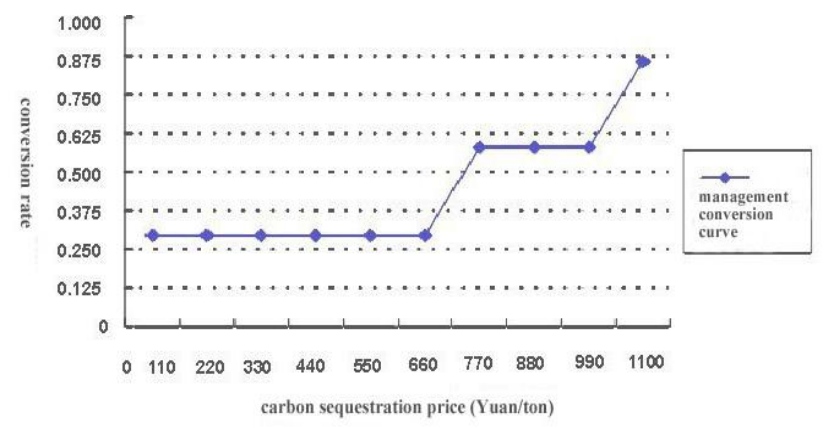

FIGURE II. CONVERSION RATE OF ZHEJIANG FORESTRY MANAGEMENT AT DIFFERENT CARBON PRICES

From the above figure, according to current carbon transaction price, the conversion rate that the forestry managers are willing to transform traditional forestry management model to carbon sequestration forestry management model is 0.298. This conversion rate will be maintained until carbon transaction price rises to 660 Yuan. After carbon transaction price breaks through 660 Yuan, the conversion rate of forestry managers willing to transform traditional forestry management model to carbon sequestration forestry management model will rise continuously. When carbon price reaches 1100 Yuan, the conversion rate will achieve 0.875 .

\section{CONCLUSION AND DISCUSSION}

This paper analyzes the mechanism and factors of forestry carbon sequestration market development in Zhejiang Province based on the theoretical analysis and filed research, then draws a conclusion that there is great development potential in the forestry carbon sequestration market of Zhejiang and all of the market subjects make active response to the market 
development: the demand subject's (enterprises and the public) willingness to pay for forestry carbon sequestration reaches up to $76.2 \%$, the main suppliers' (farmers and village collectives) willingness to be engaged in the forestry carbon sequestration trade reaches up to $82.6 \%$, and the governments' willingness to push forward the market development reaches up to $89.3 \%$. In addition, this paper constructs a carbon transaction price conversion coefficient model based on market response mechanism through theoretical research and empirical analysis of the response status of Zhejiang voluntary carbon markets development, calculates the conversion rate of Zhejiang traditional forestry management into carbon sequestration forestry management in different carbon price level and then carries out a simulation of the development trend of Zhejiang forestry management based on carbon markets response mechanism. The results show that carbon price of Zhejiang voluntary carbon market will rise from the current 110 Yuan to 1100 Yuan in future 20 years, with the rise in carbon price, rational forestry management subject will continue to realize the conversion from traditional forestry management to carbon sequestration forestry management, when carbon price reaches 1100 Yuan, the conversion rate will achieve 0.875. However, the further issues to be discussed including:

1) From current transaction practice of Zhejiang voluntary carbon market, the actual carbon transaction price is far below 110 Yuan/t-C. The main reason why these projects could be traded at such a low price is current voluntary emission reduction projects organized by the state are public welfare programs aiming at multiple benefits of forestry management. The basic goal is to drive the process of forest ecological benefit valuation. Carbon sequestration price paid by enterprises more reflects the subsidy significance of the government, instead of market trading significance.

2) Since wood price keeps high and shows a rising trend year by year, forestry managers show a significant channel dependence on traditional wood management model. Besides, since current forestry carbon sequestration transaction cost is too high and the management risk is large, many forestry managers flinch to participate in forestry carbon sequestration transaction. It increases economic pressures of both trading parties and meanwhile reduces the attraction of carbon sequestration project to both trading parties, thus seriously restricting the development of voluntary carbon market.

3) Whether the government will levy carbon tax will be the ultimate driving force deciding whether Zhejiang province and even the whole China's domestic forestry carbon market can really form and develop rapidly. Although China need not undertake emission reduction obligation currently, with large economic aggregate and rapid development, total amount of carbon dioxide emission in China has exceeded America, ranking the first in the world. Thus, the pressure of China's carbon emission reduction will be large in the future. As a responsible power, future inevitable choice of China's government is to implement strict, internationally compatible carbon tax policy ${ }^{[13]}$. Zhejiang, as the fifth experimental site developing eco-province construction, the voluntary carbon market will certainly meet greater development opportunity in the near future.

\section{ACKNOWLEDGMENT}

This study was supported by National Natural Science Foundation of China (Reference No. 71473230, Reference No. 71803180) and Natural Science Foundation of Zhejiang Province (Reference No. Q17G030042).

\section{REFERENCES}

[1] Dong Hengyu. Carbon Sequestration Theory Study and Its Significance[N]. Inner Mongolia Daily, September 30th, 2011.

[2] Tan Zhixiong. The Construction of China's Forestry Carbon Sequestration Market [J]. Management Frontier, 2012.

[3] Huang,Sheng Zhong. Research and application of wavelet neural networks of particle swarm optimization algorithm in the performance prediction of centrifugal compressor. Advanced Materials Research,2011, Volume187:271-276.

[4] Hamilton K,Sjardin M,Shapiro A,et al.Fortifying the foundation: state of the voluntary carbon markets 2009 [EB/OL].
[ http://www.ecosystemmarketplace.com/documents/c_documents/State Of The VoluntaryCarbonMarkets-2009.pdf.

[5] Iverson L R,Prasad A M,Matthews S N,et al. Estimating potential habitat for 134 eastern US tree under six climate scenarios[J].Forest Ecology and Management, 2008,254:390-406

[6] Hee, H. S. Forest landscape models, definition,characterization, and classification[J]. Forest Ecology and Management, 2008, 254: 484-498

[7] Canadell, J. G., Raupach, M. R. 2008. Forest management for climate change mitigation. Science 320: 1456-1457.

[8] Gustafson E J,Lytle D E,Swaty R,et al. Simulating the cumulative effects of multiple forest management strategies on landscape measures of forest sustainability[J].Landscape Ecology, 2007, 22:141-156

[9] Hoen, H. F., Solberg, B. 1997.CO2-taxing, timber rotations, and market implications. Critical Reviews in Environmental Science and Technology 27 (Special Issue): 151-162

[10] Wang Xing-zhi, GAO Jian-zhong. Analysis of Forest Carbon sink Market From the Perspective of Market player[J]. Forest Inventory and Planning, 2011,36 (1) :117-119.

[11] Fang G, Xiaolin,GAO Lan.Research Status of Forestry Carbon Market and Proposals of Further Development[J]. Ecological Economy, 2011 (3): 96-99.

[12] Murray, B.C. 2000.Carbon values, reforestation, and 'perverse' incentives under the Kyoto protocol: an empirical analysis. Mitigation and Adaptation Strategies for Global Change 5: 271-295.

[13] Canadell, J. G., Raupach, M. R. 2008. Forest management for climate change mitigation. Science 320: 1456-1457. 